\title{
Rolling Element Bearing Fault Diagnosis Using Laplace-Wavelet Envelope Power Spectrum
}

\author{
Khalid F. Al-Raheem, ${ }^{1}$ Asok Roy, ${ }^{2}$ K. P. Ramachandran,, ${ }^{1}$ D. K. Harrison, ${ }^{2}$ and Steven Grainger ${ }^{2}$ \\ ${ }^{1}$ Department of Mechanical and Industrial Engineering, Caledonian College of Engineering, P.O. Box 2322, CPO Seeb, PC 111, Oman \\ ${ }^{2}$ School of Engineering Science and Design, Glasgow Caledonian University, Glasgow G40BA, UK
}

Received 1 July 2006; Revised 19 December 2006; Accepted 1 April 2007

Recommended by Alex Kot

The bearing characteristic frequencies (BCF) contain very little energy, and are usually overwhelmed by noise and higher levels of macro-structural vibrations. They are difficult to find in their frequency spectra when using the common technique of fast fourier transforms (FFT). Therefore, Envelope Detection (ED) has always been used with FFT to identify faults occurring at the BCF. However, the computation of the ED is suffering to strictly define the resonance frequency band. In this paper, an alternative approach based on the Laplace-wavelet enveloped power spectrum is proposed. The Laplace-Wavelet shape parameters are optimized based on Kurtosis maximization criteria. The results for simulated as well as real bearing vibration signal show the effectiveness of the proposed method to extract the bearing fault characteristic frequencies from the resonant frequency band.

Copyright (c) 2007 Khalid F. Al-Raheem et al. This is an open access article distributed under the Creative Commons Attribution License, which permits unrestricted use, distribution, and reproduction in any medium, provided the original work is properly cited.

\section{INTRODUCTION}

The predictive maintenance philosophy of using vibration information to lower operating costs and increase machinery availability is gaining acceptance throughout industry. Since most of the machinery in a predictive maintenance program contains rolling element bearings, it is imperative to establish a suitable condition monitoring procedure to prevent malfunction and breakage during operation.

The hertzian contact stresses between the rolling elements and the races are one of the basic mechanisms that initiate a localized defect. When a rolling element strikes a localized defect, an impulse occurs which excites the resonance of the structure. Therefore, the vibration signature of the damaged bearing consists of exponentially decaying sinusoid having the structure resonance frequency. The duration of the impulse is extremely short compared with the interval between impulses, and so its energy is distributed at a very low level over a wide range of frequency and hence, can be easily masked by noise and low-frequency effects. The periodicity and amplitude of the impulses are governed by the bearing operating speed, location of the defect, geometry of the bearing, and the type of the bearing load. The theoretical estimations of these frequencies are denoted as bearing characteristics frequencies $(\mathrm{BCF})$; see the appendix.
The rolling elements experience some slippage as the rolling elements enter and leave the bearing load zone. As a consequence, the occurrence of the impacts never reproduce exactly at the same position from one cycle to another, moreover, when the position of the defect is moving with respect to the load distribution of the bearing, the series of impulses is modulated in amplitude. However, the periodicity and the amplitude of the impulses experience a certain degree of randomness [1-4]. In such case, the signal is not strictly periodic, but can be considered as cyclo-stationary (periodically time-varying statistics), then the cyclic second-order statistics (such as cyclic autocorrelation and cyclic spectral density) are suited to demodulate the signal and extract the fault feature [5-7]. All these make the bearing defects very difficult to detect by conventional FFT-spectrum analysis which assumes that the analyzed signal to be strictly periodic. A method of conditioning the signal before the spectrum estimation takes places is necessary.

To overcome the modulation problem, several signal envelope demodulation techniques have been introduced. In high-frequency resonance technique (HFRT), an envelope detector demodulates the passband filtered signal and the frequency spectrum is determined by FFT technique [8]. Another well-established method is based on the Hilbert transform $[9,10]$. The inconvenience of the envelope 
demodulation techniques is that the most suitable passband must be identified before the demodulation takes place.

The wavelet transform provides powerful multiresolution analysis in both time and frequency domain and thereby becomes a favored tool to extract the transitory features of nonstationary vibration signals produced by the faulty bearing [11-16]. The wavelet analysis results in a series of wavelet coefficients, which indicate how close the signal is to the particular wavelet. In order to extract the fault feature of signals more effectively, an appropriate wavelet base function should be selected. Morlet wavelet is mostly applied to extract the rolling element bearing fault feature because of the large similarity with the impulse generated by the faulty bearing [17-20]. The impulse response wavelet is constructed and applied to extract the feature of fault vibration signal in [21]. A number of wavelet-based functions are proposed for mechanical fault detection with high sensitivity in [22], and the differences between single and doublesided Morlet wavelets are presented. An adaptive wavelet filter based on single-sided Morlet wavelet is introduced in [23].

The Laplace wavelet is a complex, single-sided damped exponential formulated as an impulse response of a single mode system to be similar to data feature commonly encountered in health monitoring tasks. It is applied to the vibration analysis of an actual aircraft for aerodynamic and structural testing [24], and to diagnose the wear fault of the intake valve of an internal combustion engine [25].

In this paper, an alternative approach for detecting localized faults in the outer and inner races of a rolling element bearing using the envelope power spectrum of the Laplace wavelet is investigated. The wavelet shape parameters are optimized by maximizing the kurtosis of the wavelet coefficients to ensure a large similarity between the wavelet function and the generated fault impulse.

This paper is organized as follows. In the next section, the vibration model for a rolling bearing with outer- and inner-race faults is introduced. Then in Section 3, the procedures of the proposed approach are set up. In Section 4, the implementation of the proposed approach for detection of localized ball bearing defects for both simulated and actual bearing vibration signals is presented. Conclusions are finally given in Section 5.

\section{VIBRATION MODEL FOR ROLLING ELEMENT BEARING LOCALIZED DEFECTS}

Every time the rolling element strikes a defect in the raceway or every time a defect in the rolling element hits the raceway, a force impulse of short duration is produced which in turn excites the natural frequencies of the bearing parts and housing structure. The structure resonance in the system acts as an amplifier of low-energy impacts. Therefore, the overall vibration signal measured on the bearing shows a pattern consisting of a succession of oscillating bursts dominated by the major resonance frequency of the structure.
The response of the bearing structure as an underdamped second-order mass-spring-damper system to a single impulse force is given by

$$
S(t)=C e^{-\left(\xi / \sqrt{1-\xi^{2}}\right) \omega_{d} t} \sin \left(\omega_{d} t\right)
$$

where $\zeta$ is the damping ratio and $\omega_{d}$ is the damped natural frequency of the bearing structure.

As the shaft rotates, this process occurs periodically every time a defect hits another part of the bearing and its rate of occurrence is equal to one of the BCF. In reality, there is a slight random fluctuation in the spacing between impulses because the load angle on each rolling element changes as the rolling element passes through the load zone. Furthermore, the amplitude of the impulse response will be modulated as a result of the passage of the fault through the load zone,

$$
x(t)=\sum_{i} A_{i} S\left(t-T_{i}\right)+n(t)
$$

where $S\left(t-T_{i}\right)$ is the waveform generated by the $i$ th impact at the time $T_{i}$, and $T_{i}=i T+\tau_{i}$, where $T$ is the average time between two impacts, and $\tau_{i}$ describe the random slips of the rolling elements. $A_{i}$ is the time varying amplitudedemodulation, and $n(t)$ is an additive background noise which takes into account the effects of the other vibrations in the bearing structure.

Figures 1 and 2 show the impulses and the acceleration signals $\left(d^{2} x(t) / d t^{2}\right)$ generated by the model in (2) with random $\operatorname{slip}(\tau)$ of 10 percent of the period $T$ and signal to noise ratio of $0.6 \mathrm{~dB}$ for outer-race and inner-race bearing faults, respectively.

\section{ENVELOPED WAVELET POWER SPECTRUM}

The waveform $x(t)$ in (2) can be viewed as a carrier signal at a resonant frequency of the bearing housing (high frequency) modulated by the decaying envelope. The frequency of interest in the detection of bearing defects is the modulating frequency (low frequency). The goal of the enveloping approach is to replace the oscillation caused by each impact with a single pulse over the entire period of the impact.

The Laplace wavelet is a complex, analytical, and singlesided damped exponential, and it is given by

$$
\Psi(t)= \begin{cases}A e^{-\left(\beta / \sqrt{1-\beta^{2}}\right) \omega_{c} t} e^{-j \omega_{c} t}, & t \geq 0 \\ 0, & t<0\end{cases}
$$

where $\beta$ is the damping factor that controls the decay rate of the exponential envelope in the time domain and hence regulates the resolution of the wavelet, and it simultaneously corresponds to the frequency bandwidth of the wavelet in the frequency domain. The frequency $\omega_{c}$ determines the number of significant oscillations of the wavelet in the time domain 


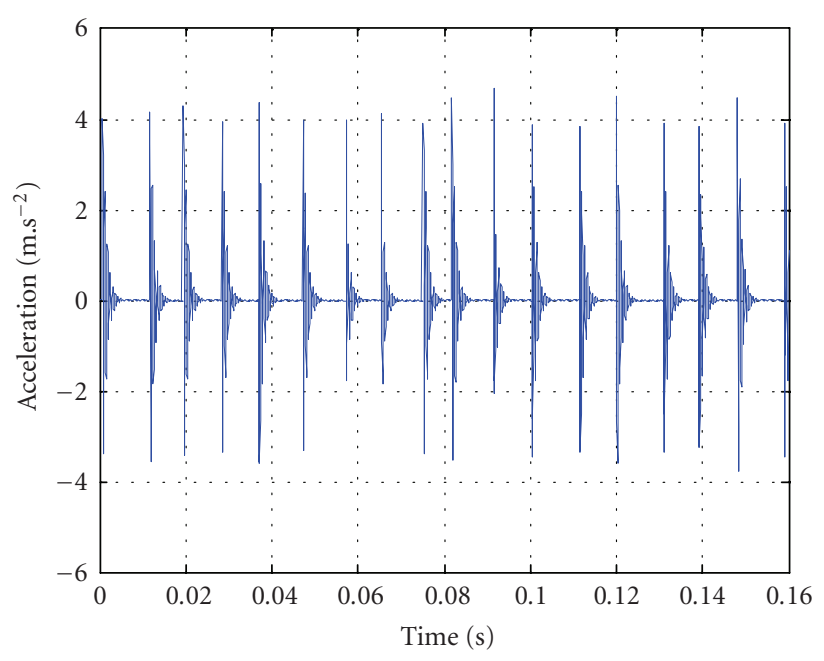

(a)

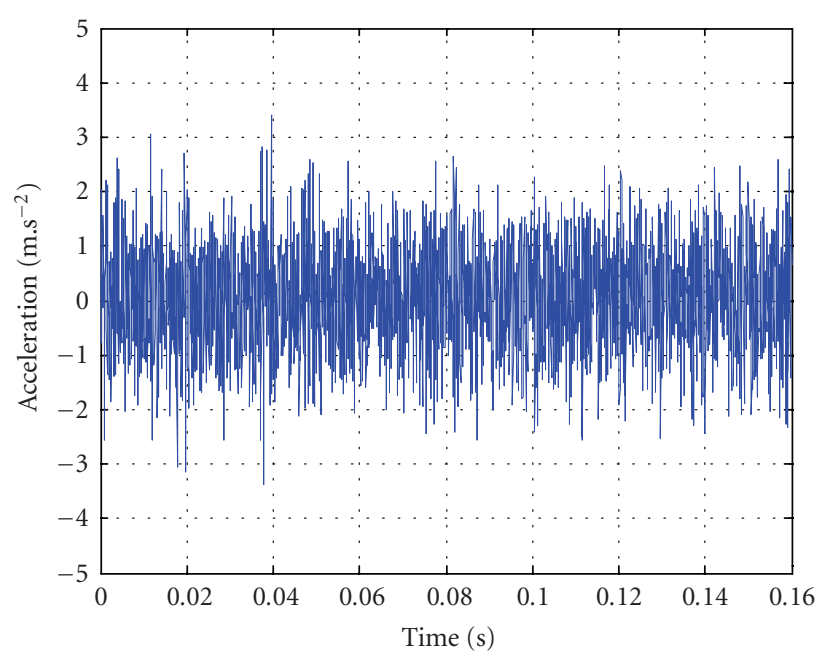

(b)

FIgURE 1: The simulated impulses (a) and the vibration signal (b) for a rolling bearing with outer-race fault.

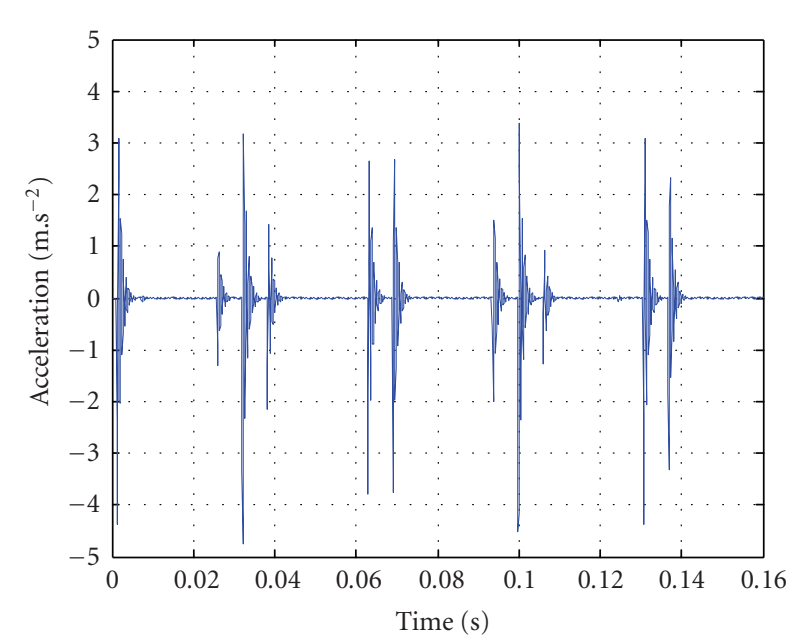

(a)

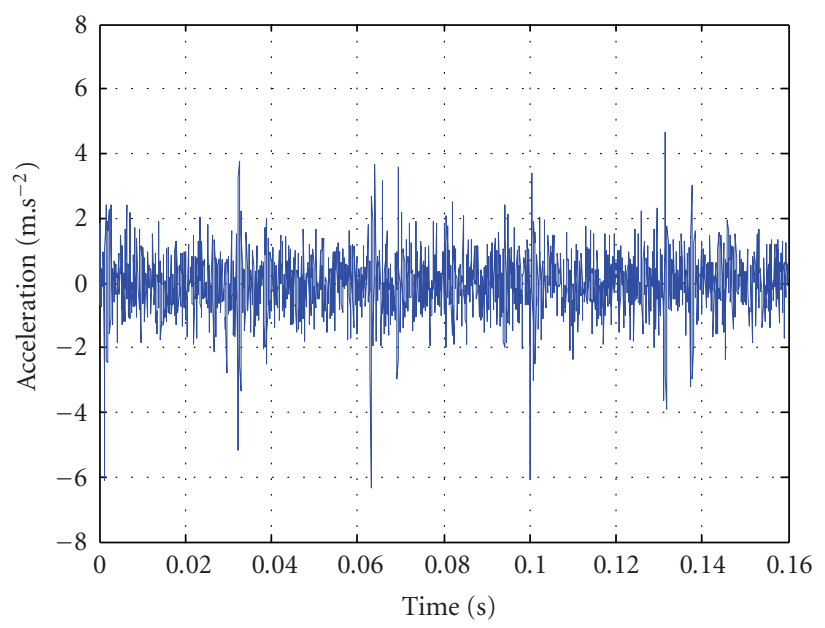

(b)

FIgURE 2: The simulated impulses (a) and the vibration signal (b) for a rolling bearing with inner-race fault.

and corresponds to the wavelet centre frequency in frequency domain, and $A$ is an arbitrary scaling factor. Figure 3 shows the Laplace wavelet, its real part, imaginary part, and its spectrum.

It is possible to find optimal values of $\beta$ and $\omega_{c}$ for a given vibration signal by adjusting the time-frequency resolution of the Laplace wavelet to the decay rate and frequency of impulses to be extracted. Kurtosis is an indicator that reflects the "peakiness" of a signal, which is a property of the impulses and also it measures the divergence from a fundamental Gaussian distribution. A high kurtosis value indicates high-impulsive content of the signal with more sharpness in the signal intensity distribution. Figure 4 shows the kurtosis value and the intensity distribution for a white noise signal, pure impulsive signal, and impulsive signal mixed with noise.

The objective of the Laplace wavelet shape optimization process is to find out the wavelet shape parameters $(\beta$ and $\omega_{c}$ ) which maximize the kurtosis of the wavelet transform output;

$$
\begin{aligned}
& \operatorname{Optimal}\left(\beta, \omega_{c}\right) \\
& =\max \cdot\left[\frac{\sum_{n=1}^{N} \mathrm{WT}^{4}\left(x(t), \psi_{\beta, \omega_{c}}(t)\right)}{\left[\sum_{n=1}^{N} \mathrm{WT}^{2}\left(x(t), \psi_{\beta, \omega_{c}}(t)\right)\right]^{2}}\right] .
\end{aligned}
$$

The wavelet transform (WT) of a finite energy signal $x(t)$, with the mother wavelet $\psi(t)$, is the inner product of $x(t)$ 


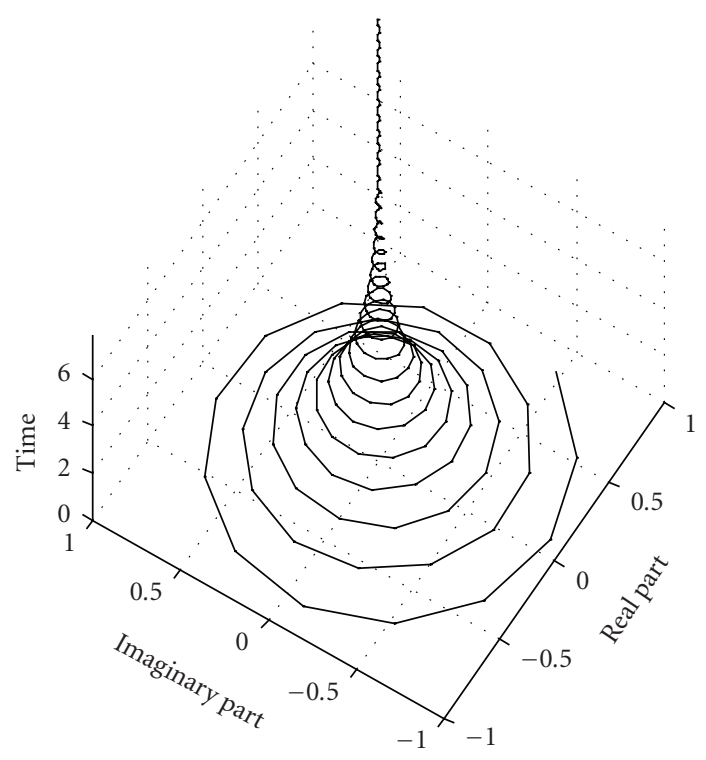

(a)

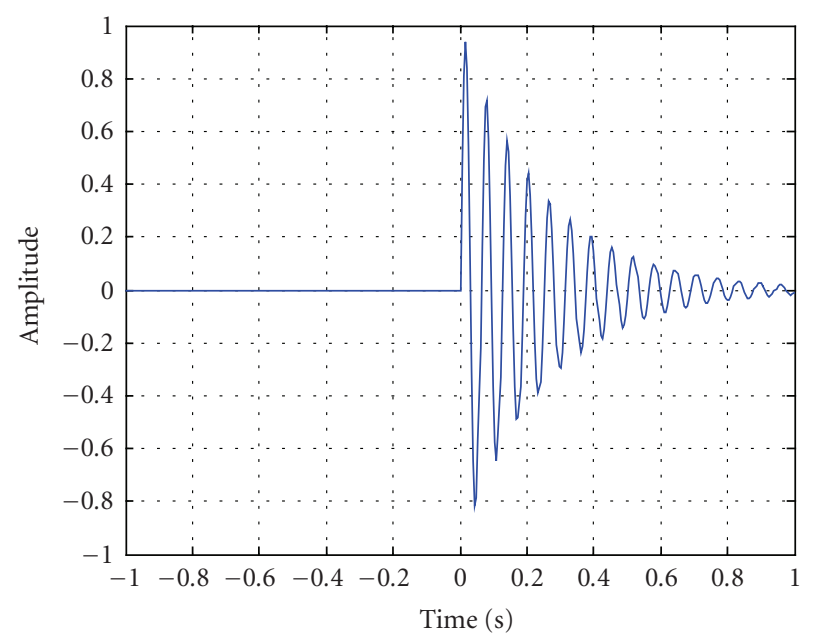

(c)

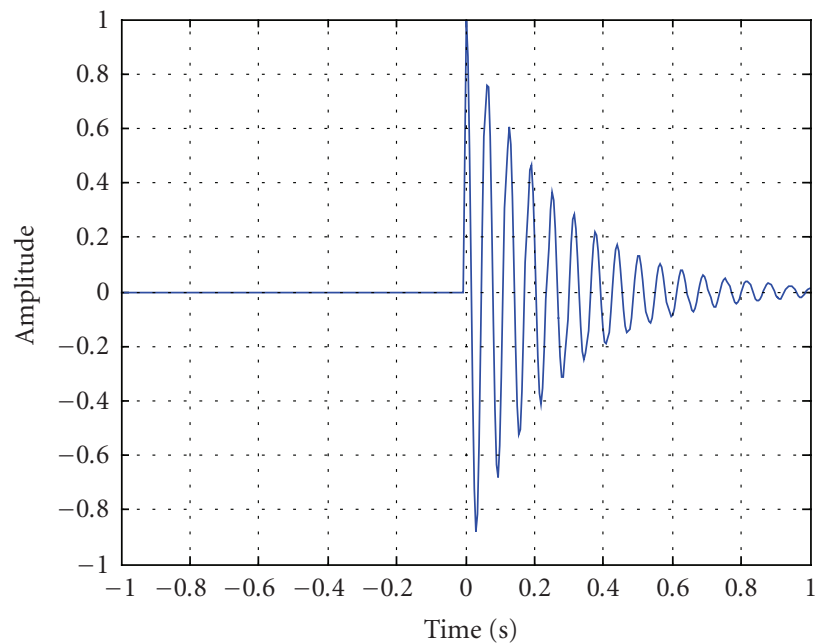

(b)

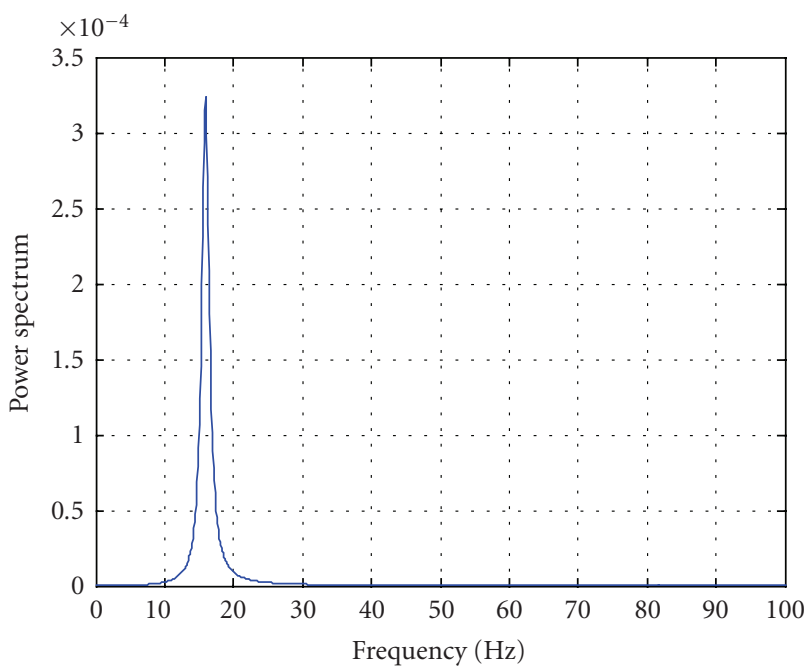

(d)

FIgURE 3: (a) The Laplace wavelet, (b) the real part, (c) the imaginary part, and (d) its spectrum.

with a scaled and conjugate wavelet $\psi_{a, b}^{*}$, since the analytical and complex wavelet is employed to calculate the wavelet transform. The result of the WT is also an analytical signal,

$$
\begin{aligned}
\mathrm{WT}\{x(t), a, b\} & =\left\langle x(t), \psi_{a, b}(t)\right\rangle=\frac{1}{\sqrt{a}} \int x(t) \Psi_{a, b}^{*}(t) d t \\
& =\operatorname{Re}[\mathrm{WT}(a, b)]+j \operatorname{Im}[\mathrm{WT}(a, b)] \\
& =A(t) e^{i \theta(t)},
\end{aligned}
$$

where $\psi_{a, b}$ is a family of daughter wavelets, defined by the dilation parameter $a$ and the translation parameter $b$, the factor
$1 / \sqrt{ } a$ is used to ensure energy preservation. The time-varying function $A(t)$ is the instantaneous envelope of the resulting wavelet transform (EWT) which extracts the slow time variation of the signal, and is given by

$$
\begin{aligned}
A(t) & =\operatorname{EWT}(a, b) \\
& =\sqrt{\{\operatorname{Re}[\mathrm{WT}(a, b)]\}^{2}+\{\operatorname{Im}[\mathrm{WT}(a, b)]\}^{2}} .
\end{aligned}
$$

For each wavelet, the inner product results in a series of coefficients which indicate how close the signal is to that particular wavelet. 

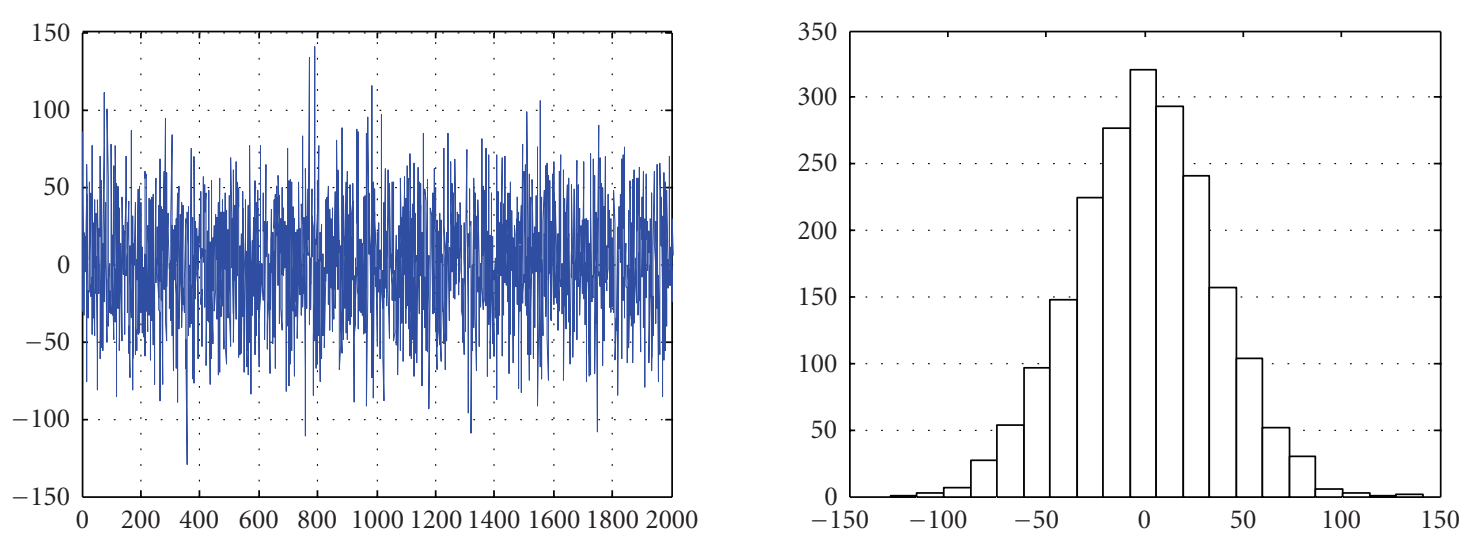

(a)
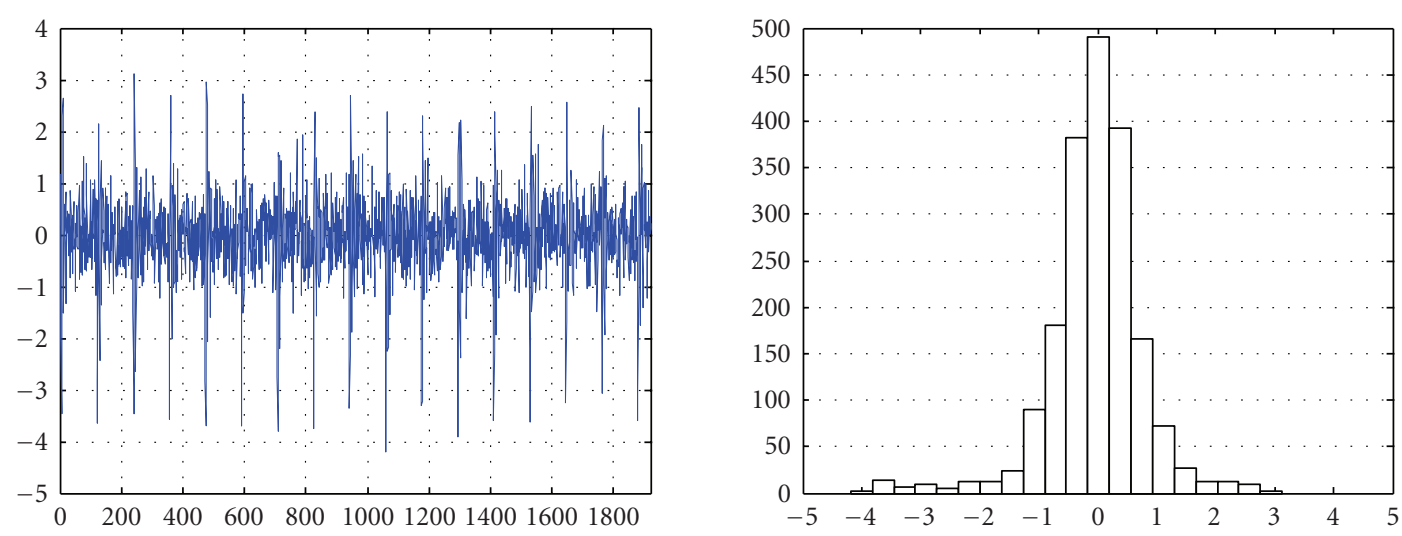

(b)
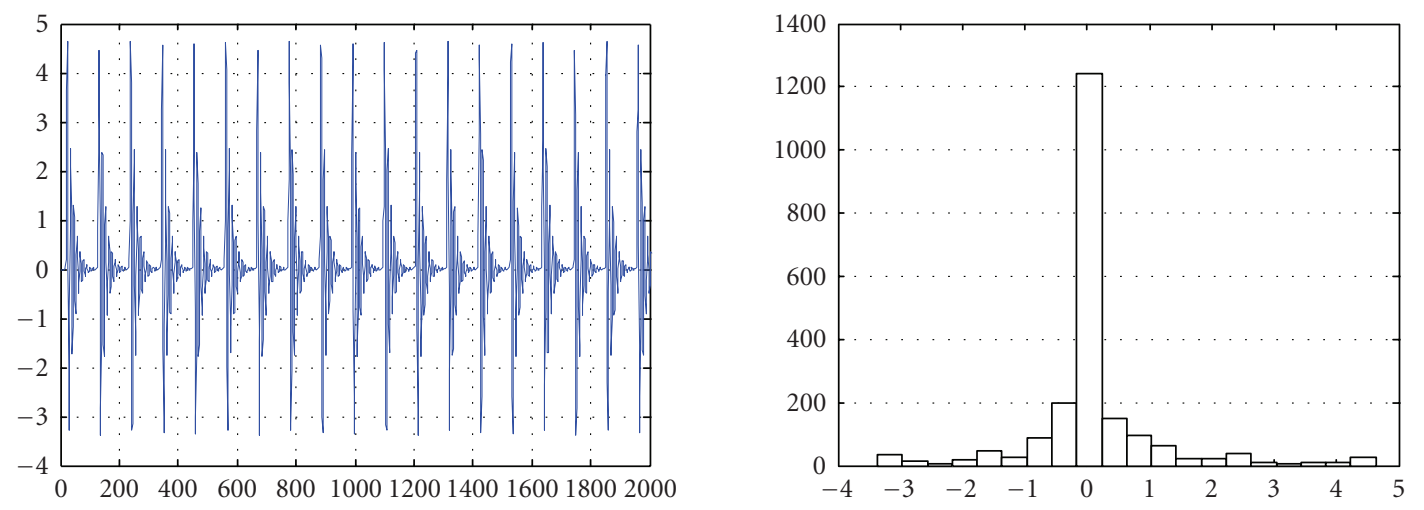

(c)

FIGURE 4: (a) The noise signal (kurtosis $=3.0843$ ), (b) the overall vibration signal (kurtosis $=7.7644$ ), and (c) outer-race fault impulses (kurtosis $=8.5312$ ) with the corresponding intensity distribution curve.

To extract the frequency content of the enveloped correlation coefficients, the scale power spectrum (WPS) (energy per unit scale) is given by

$$
\operatorname{WPS}(a, \omega)=\int_{-\infty}^{\infty}|\operatorname{SEWT}(a, \omega)|^{2} d \omega
$$

where $\operatorname{SEWT}(a, \omega)$ is the Fourier transform of $\operatorname{EWT}(a, b)$.
The total energy of the signal $x(t)$,

$$
\text { TWPS }=\int|x(t)|^{2} d t=\frac{1}{2 \pi} \int \operatorname{WPS}(a, \omega) d a .
$$

\section{IMPLEMENTATION OF WPS FOR BEARING FAULT DETECTION}

To demonstrate the performance of the proposed approach, this section presents several application examples for the 
detection of localized bearing defects. In all the examples, the Laplace wavelet is used as a WT base-function. The wavelet parameters (damping factor and centre frequency) are optimized based on maximizing the kurtosis value for the wavelet coefficients; see Figure 5.

\subsection{Application to the simulation signals}

For a rolling element bearing with pitch diameter of $51.16 \mathrm{~mm}$, ball diameter of $11.9 \mathrm{~mm}$, with 8 rolling elements and $0^{\circ}$ contact angle, the calculated BCF for an outer-race fault is $107.36 \mathrm{~Hz}$, and for an inner-race fault is $162.18 \mathrm{~Hz}$ with shaft speed of $1797 \mathrm{rev} / \mathrm{min}$. Figures 1 and 2 show the simulated time domain fault impulses and the overall vibration signal for the bearing with outer-race and innerrace faults, respectively, based on the model described in Section 2.

To evaluate the performance of the proposed method, a scale-wavelet power spectrum comparison for the Laplace wavelet and the widely used Morlet wavelet was carried out; see Figure 6. It can be found that the amplitude of the power spectrum increases further for the faulty bearing than the normal one, and the power spectrum is concentrated in the scale interval of [15-20] for Laplace wavelet compared with speared power spectrum in wide range scales for Morlet wavelet. That shows the increased effectiveness of the Laplace wavelet over the Morlet wavelet for bearing fault impulses extraction.

The FFT spectrum, the envelope spectrum using Hilbert transform, and the Laplace-wavelet transform envelope spectrum for the simulated outer- and inner-race fault vibration signals are shown in Figure 7. Figure 7 shows that the BCFs are unspecified in the FFT spectrum and unclearly defined in the envelope power spectrum but it is clearly identified in the Laplace-wavelet power spectrum for both outer- and innerrace faults. The TWPS effectively extracts the $\mathrm{BCF}, 105.5 \mathrm{~Hz}$ for outer-race fault and $164.1 \mathrm{~Hz}$ for inner-race fault and its harmonics, with side bands at rotational speed for inner-race fault as a result of amplitude modulation and it is very close to the calculated BCF.

To evaluate the robustness of the proposed technique to extract the BCF for different signal to noise ratio (SNR), and randomness in the impulses period $(\tau)$ as a result of slip variation, Figure 8 shows the TWPS for outer-race fault simulated signals for different values of $\mathrm{SNR}$, and $\tau$ as a percentage of the pulses period $(T)$.

\subsection{Application to experimental data}

A B\&K 752A12 piezoelectric accelerometer was used to collect the vibration signals for an outer-race defective, deep groove, ball bearing (with same simulated specifications) at different shaft rotational speeds. The vibration signals were transferred to the PC through a B\&K controller module type 7536 at a sampling rate of $12.8 \mathrm{KHz}$. Based on the bearing parameters, the calculated outer-race fault characteristic frequency is $0.05115 \mathrm{x}$ rpm; see Figure 9.

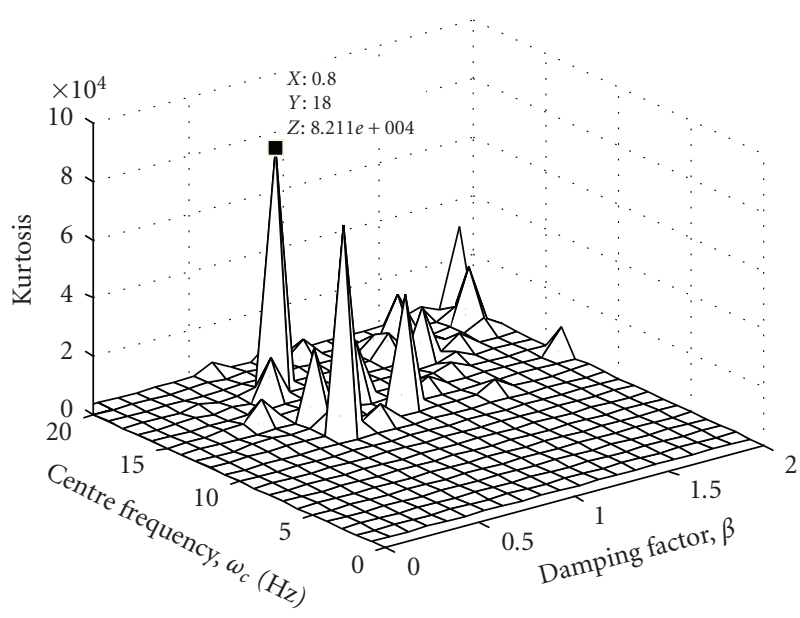

(a)

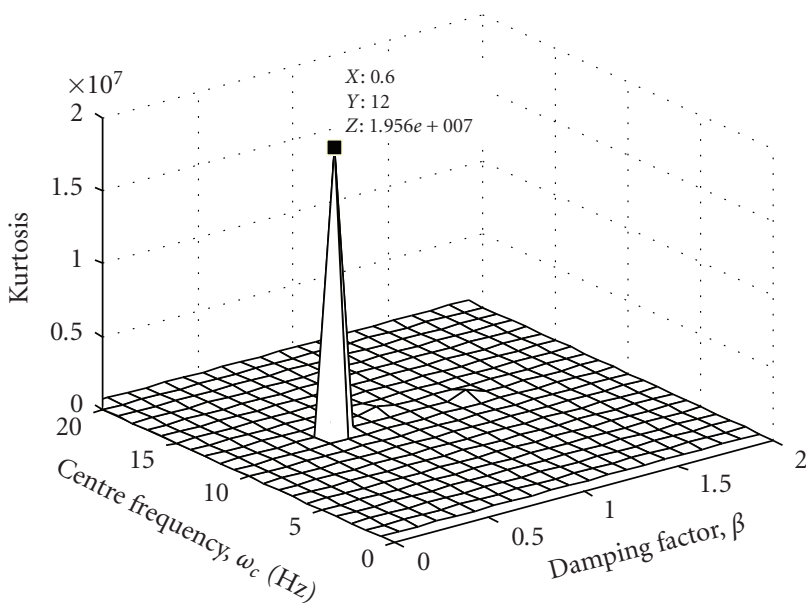

(b)

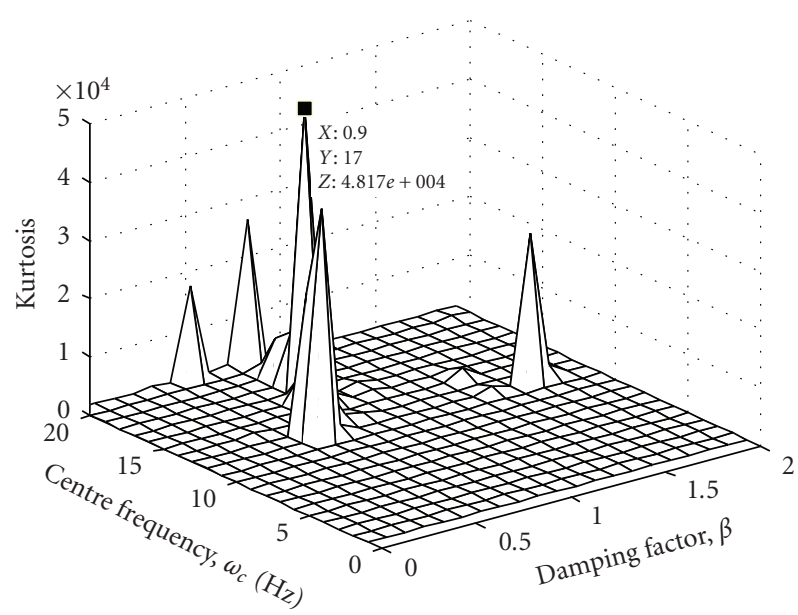

(c)

FIGURE 5: The optimal values for Laplace wavelet parameters based on maximum kurtosis for (a) simulated outer-race fault, (b) the measured outer-race fault, (c) the CWRU vibration data. 

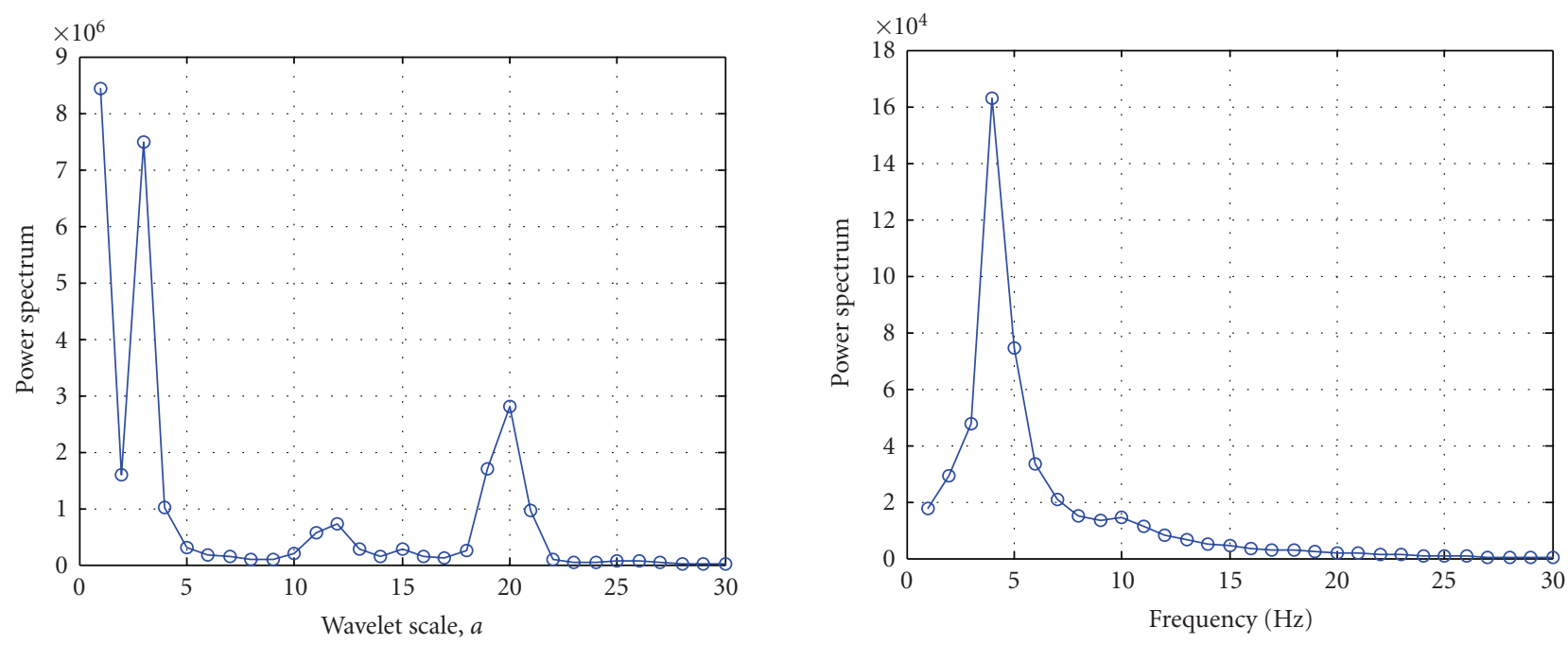

(a) New bearing
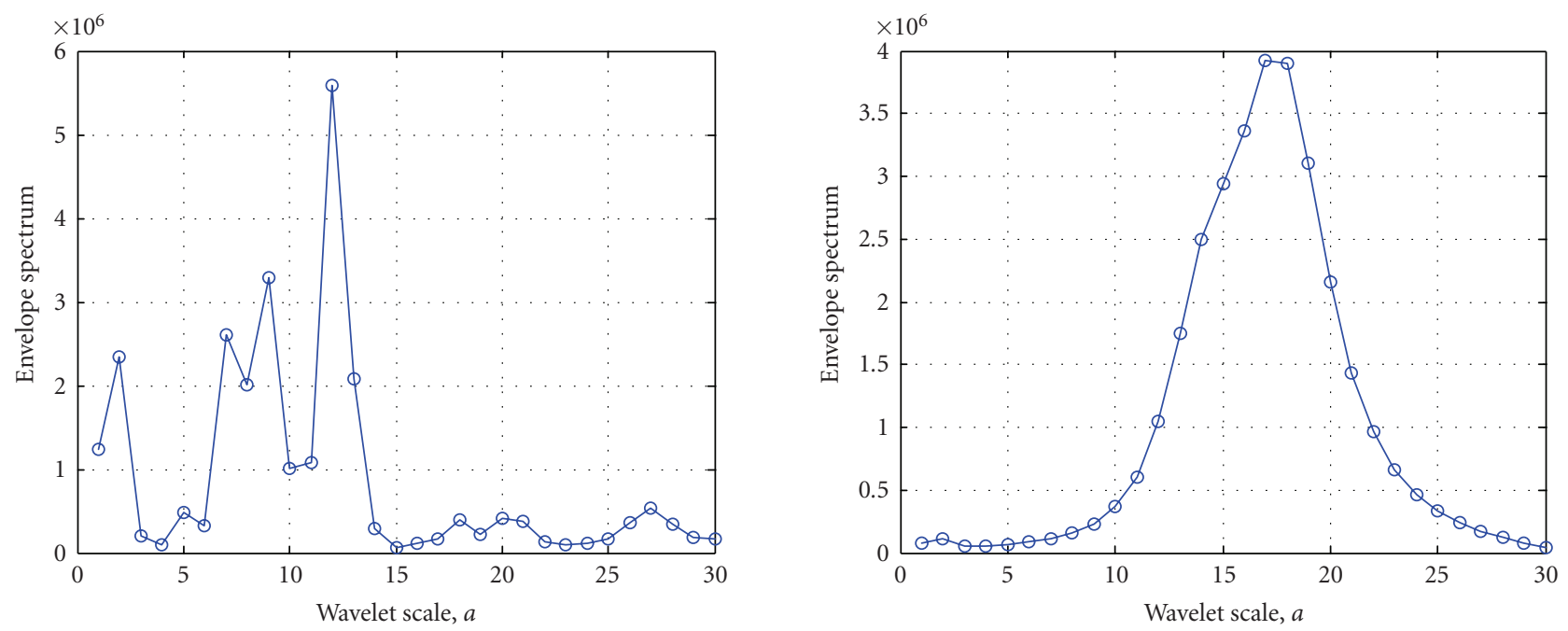

(b) Outer-race defective bearing

FIGURE 6: The wavelet-level power spectrum using (left column) Morlet wavelet, (right column) Laplace wavelet for new and outer-race defective bearing.

With application of the TWPS, the power spectrum peak values at the position of the outer-race characteristic frequency and its harmonics are easily defined; see Figure 9. It is shown that TWPS is sensitive to the variation of the BCF as a result of variation in the shaft rotational speeds; see Table 1.

\subsection{Application TWPS to vibration data}

Using the data given by the CWRU bearing centre website [26], for rolling bearings seeded with faults using electrodischarge machining (EDM). The calculated defect frequencies are $3.5848 \mathrm{x}$ shaft speed $(\mathrm{Hz})$ for outer race and $5.4152 \mathrm{x}$ shaft speed $(\mathrm{Hz})$ for inner race. The time course of the vibration signals for normal bearing and bearings with outer and inner race faults at shaft rotational speed $1797 \mathrm{rpm}$ with its corresponding TWPS are shown in Figures 10-12, respectively. The calculated BCF are $107.36 \mathrm{~Hz}$ for outer-race fault and $162.185 \mathrm{~Hz}$ for inner-race fault. The TWPS for the vibration data show spectrum peak values at $106.9 \mathrm{~Hz}$ for outer- race fault and its harmonics (Figure 11), and $161.1 \mathrm{~Hz}$ for inner-race fault with its harmonics and sidebands at shaft speed $(30 \mathrm{~Hz})$ as a result of amplitude modulation (Figure 12), which are very close to the calculated BCF. 

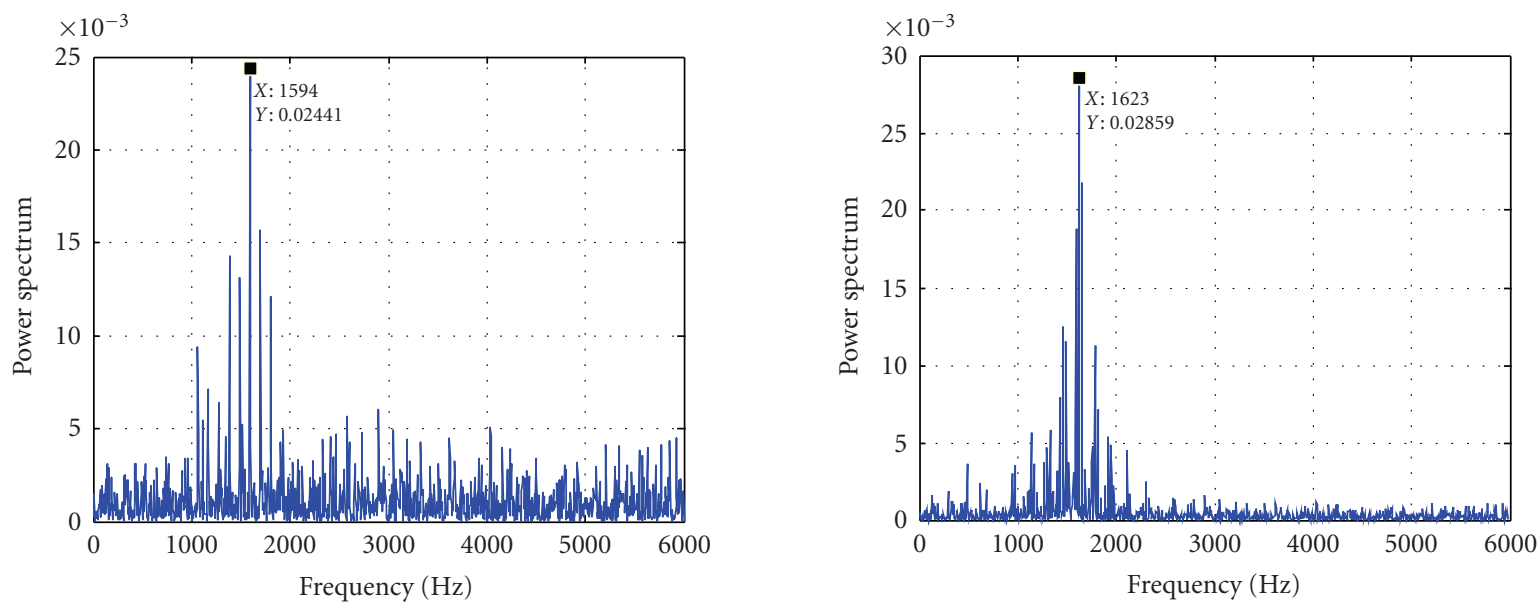

(a) FFT spectrum
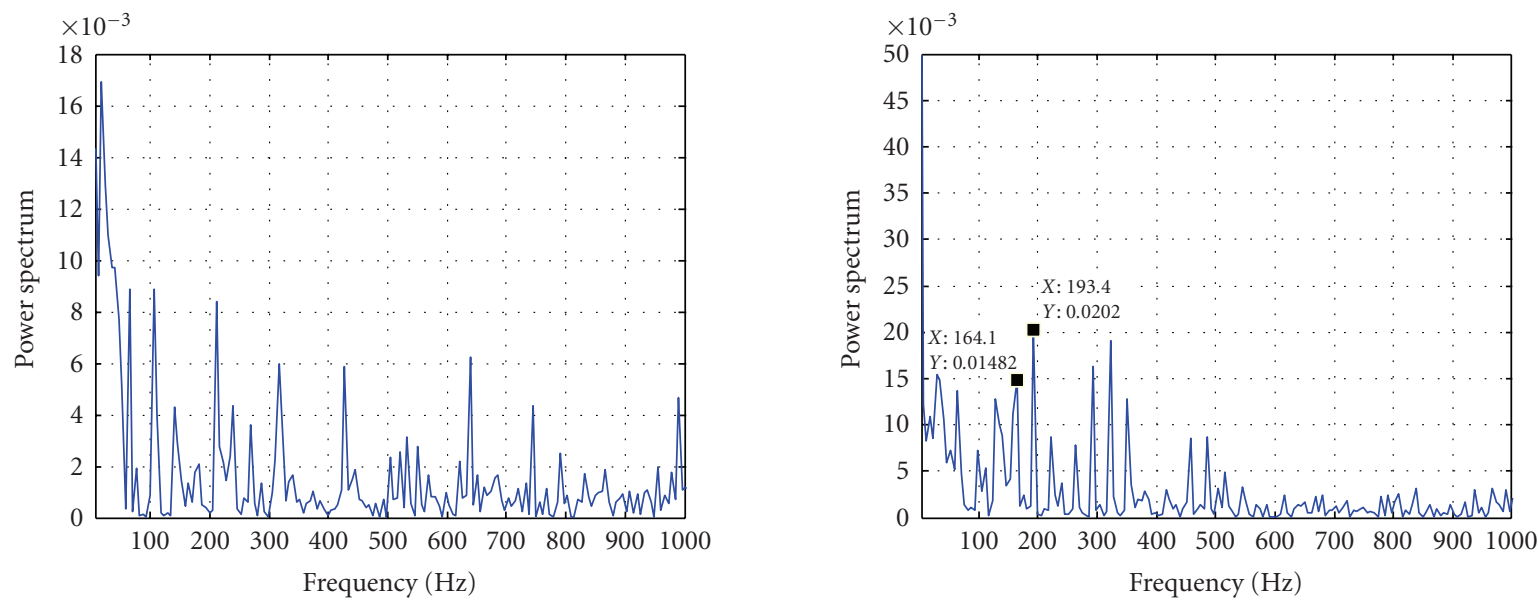

(b) ED spectrum
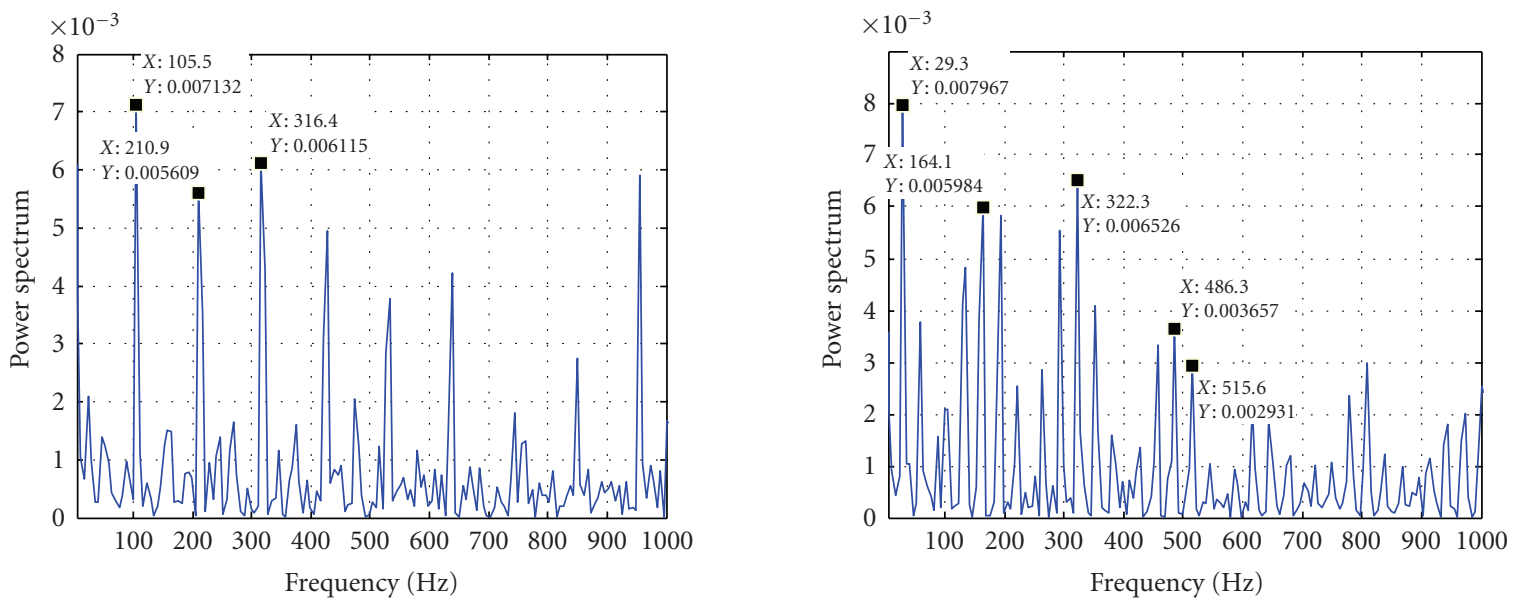

(c) Laplace wavelet spectrum

FIGURE 7: The simulated vibration signal power spectrum, the envelope power spectrum, and the Laplace-wavelet transform power spectrum, respectively, for rolling bearing with (left column) outer-race fault and (right column) inner-race fault. 


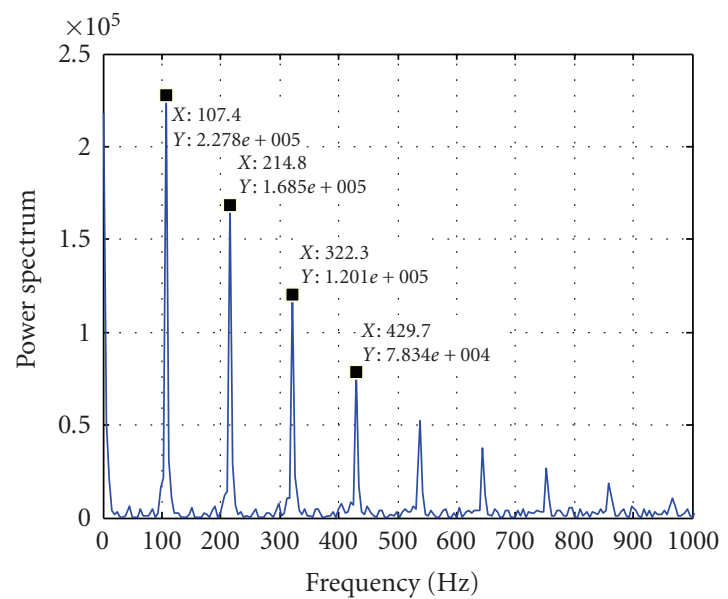

(a) $\mathrm{SNR}=3.165 \mathrm{~dB}$

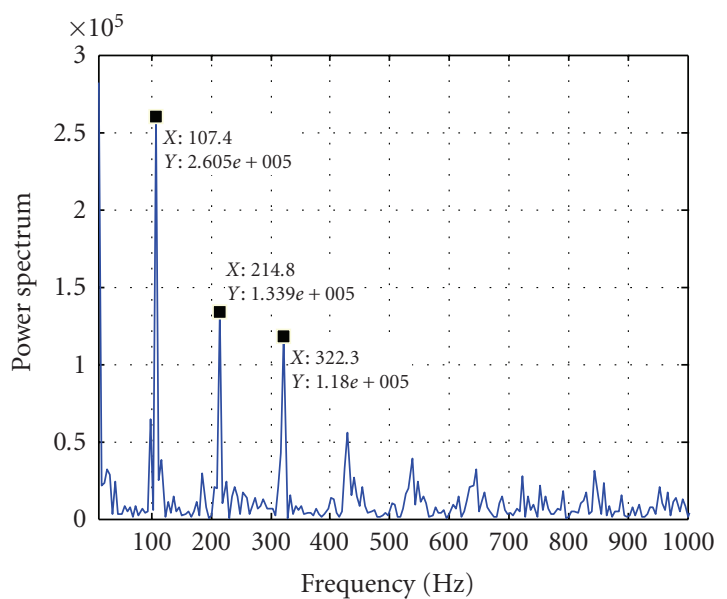

(c) $\mathrm{SNR}=0.6488 \mathrm{~dB}$

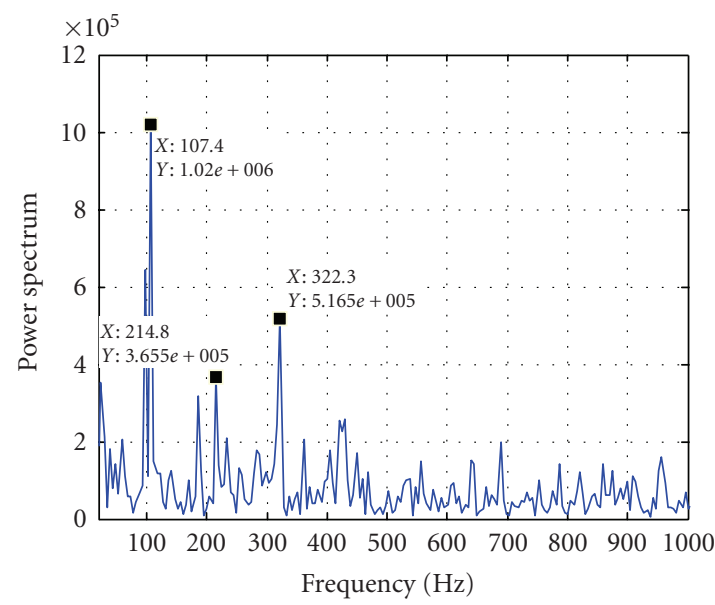

(e) $\mathrm{SNR}=0.384 \mathrm{~dB}$

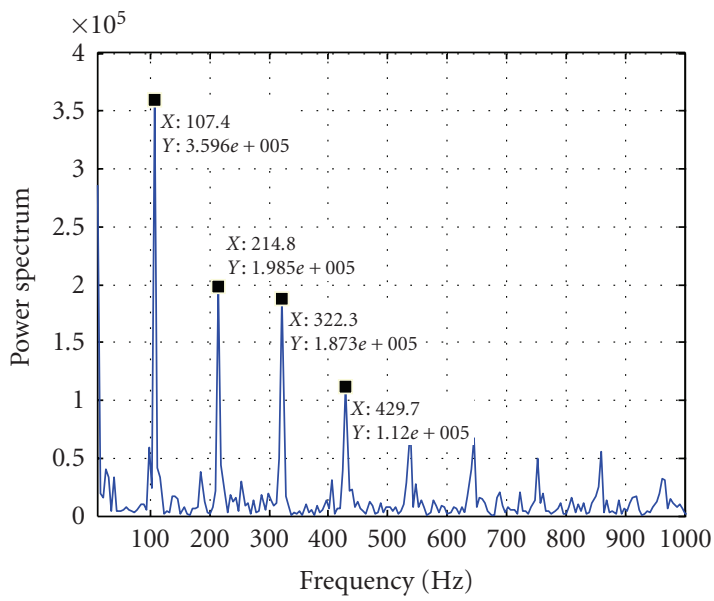

(b) $\tau=1 \%$

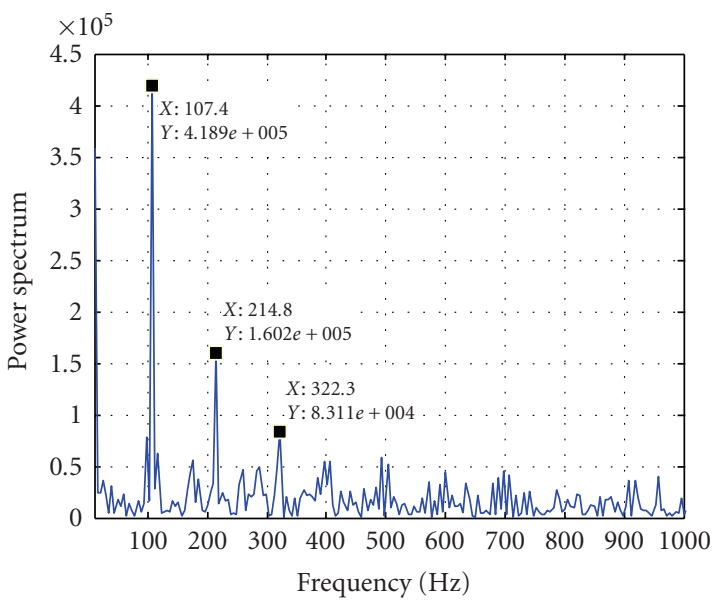

(d) $\tau=5 \%$

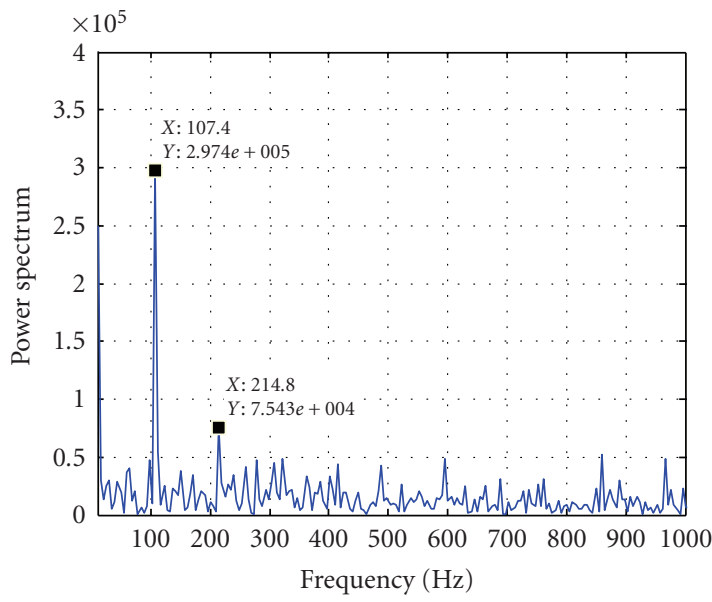

(f) $\tau=10 \%$

FIGURE 8: The TWPS for bearing with outer-race fault for different (left column) SNR and (right column) slip variation $(\tau)$. 

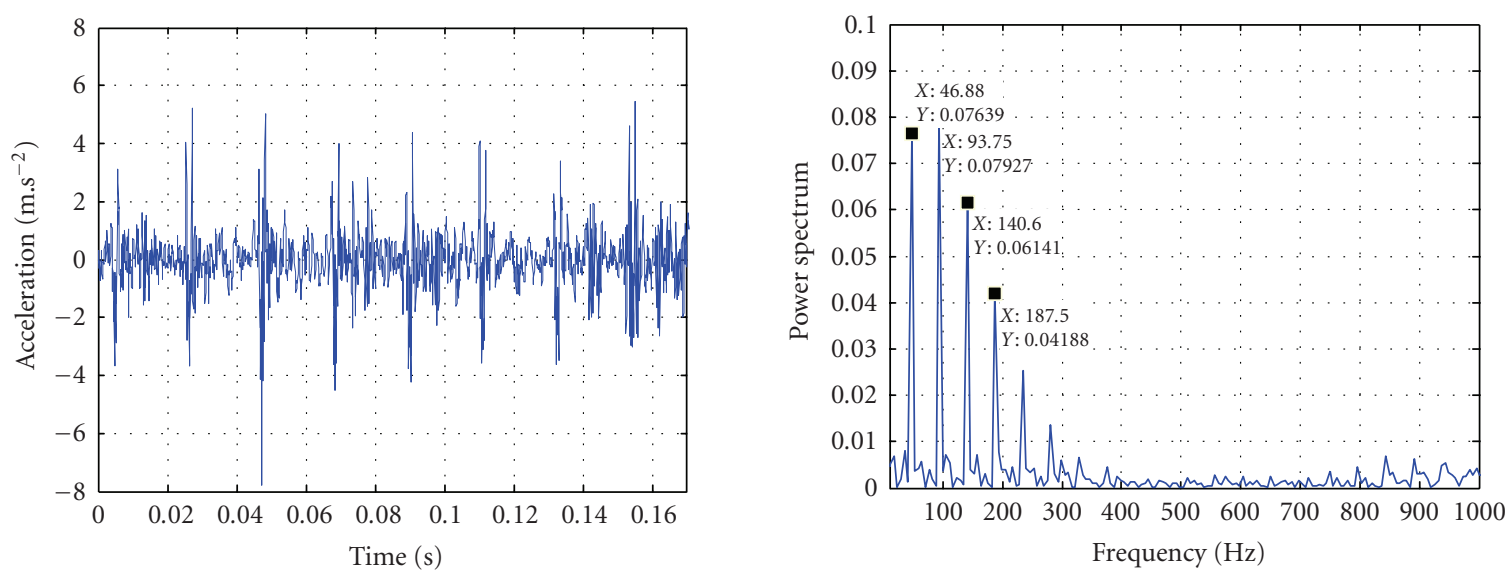

(a) $984 \mathrm{rpm}$
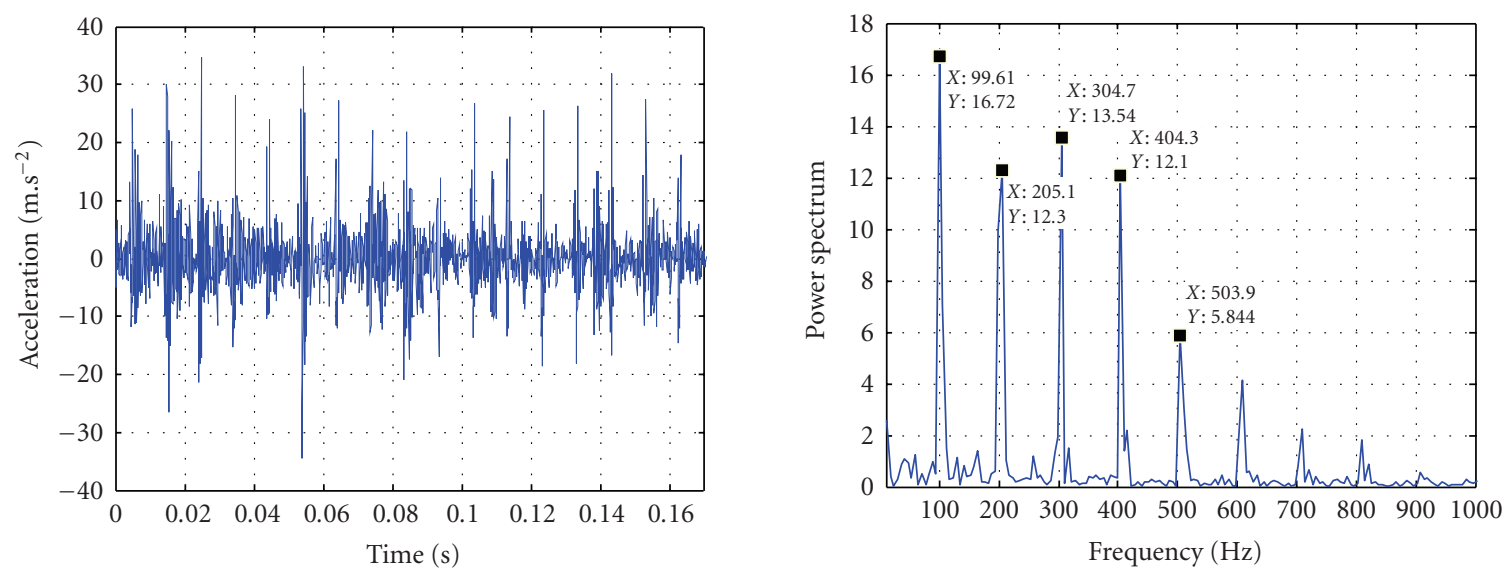

(b) $1389 \mathrm{rpm}$
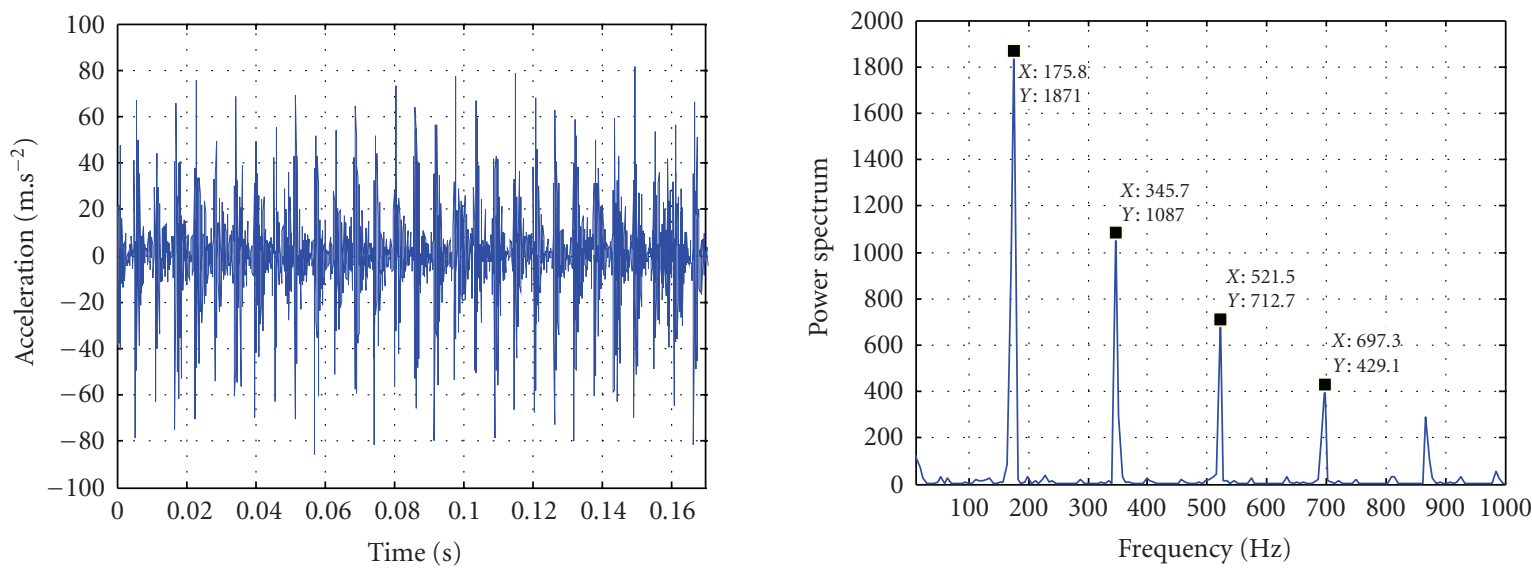

(c) $3531 \mathrm{rpm}$

FIGURE 9: The measured vibration signals for rolling bearing with outer-race fault at different shaft rotational speed (a) $984 \mathrm{rpm}$, (b) $1389 \mathrm{rpm}$, and (c) $3531 \mathrm{rpm}$. 


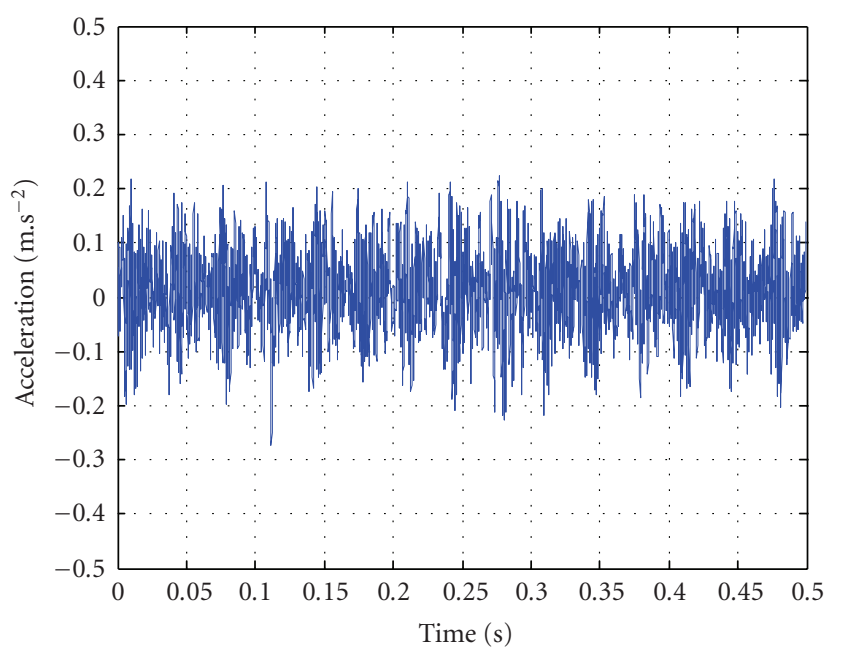

(a)

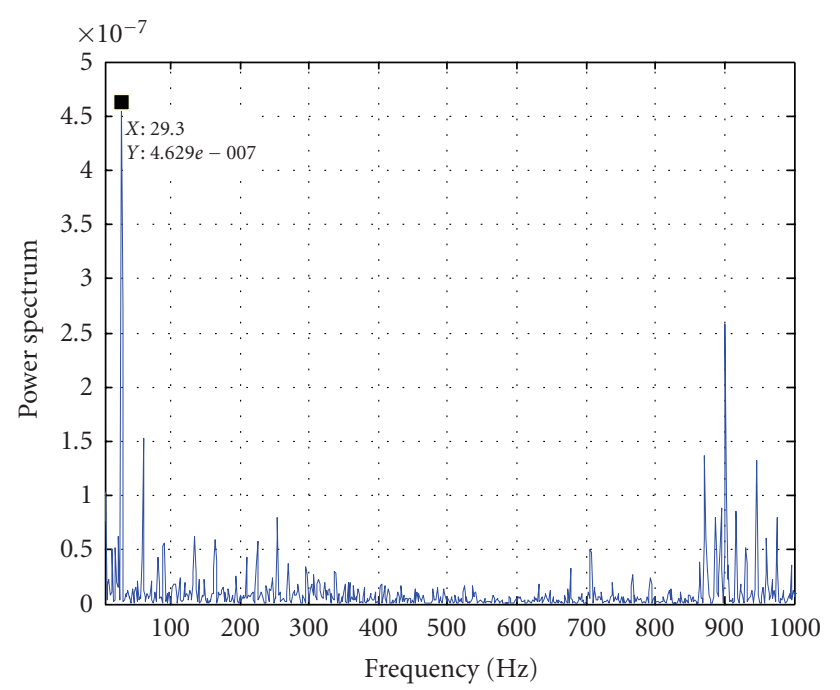

(b)

FIGURE 10: The vibration signal (a) and the corresponding TWPS (b) for new rolling bearing (CWRU data).

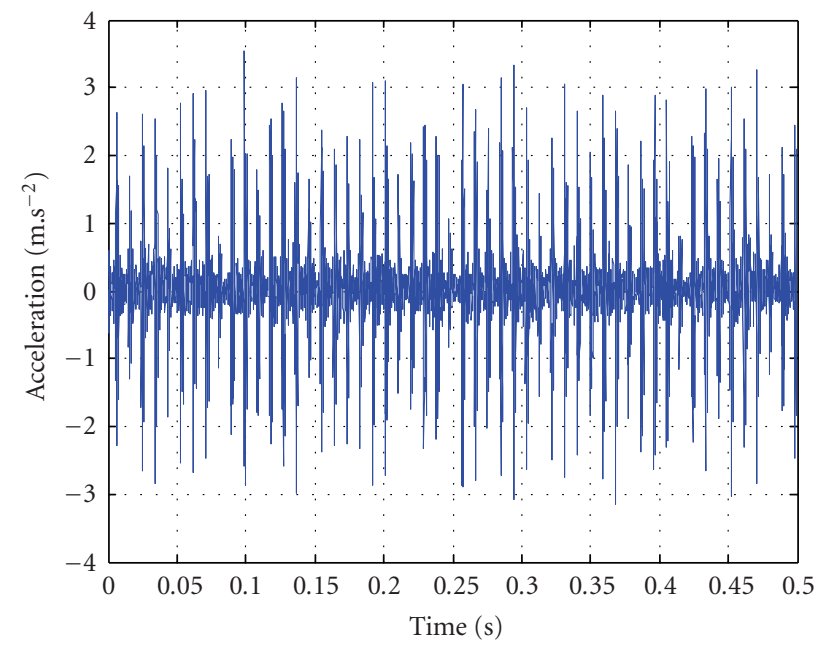

(a)

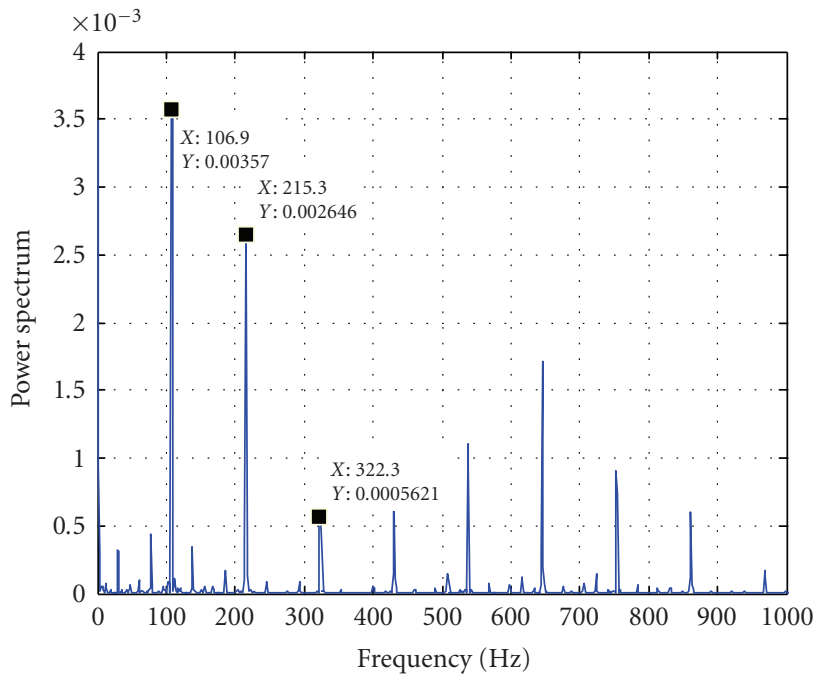

(b)

FIGURE 11: The vibration signal (a) and the corresponding TWPS (b) for rolling bearing with outer-race fault (CWRU data).

\section{CONCLUSIONS}

A new approach based on the Laplace-wavelet enveloped power spectrum (TWPS) is proposed. The wavelet shape parameters (damping factor and the centre frequency) are optimized by maximizing the kurtosis value for the vibration signal wavelet transform coefficients. The application of the proposed technique for both the simulated and real bearing vibration signals has shown the effectiveness of TWPS in
TABLE 1

\begin{tabular}{ccc}
\hline Shaft speed $(\mathrm{rpm})$ & Calculated BCF $(\mathrm{Hz})$ & TWPS peak $(\mathrm{Hz})$ \\
\hline 984 & 50.331 & 50 \\
1389 & 71.047 & 68.750 \\
3541 & 181.17 & 187.5 \\
\hline
\end{tabular}

the extraction of the BCF and its harmonics, for outer- and inner-race defective bearings from noisy vibration signals. 


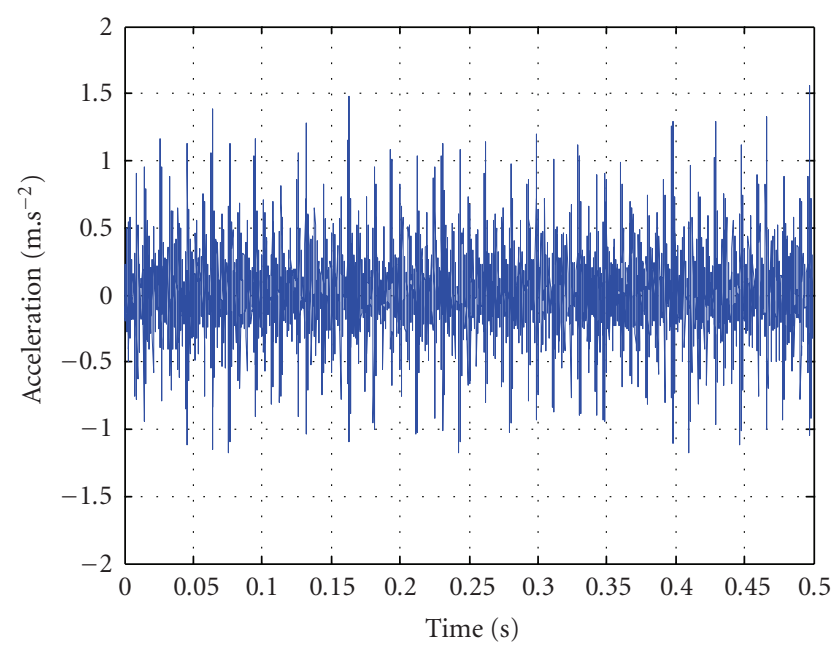

(a)

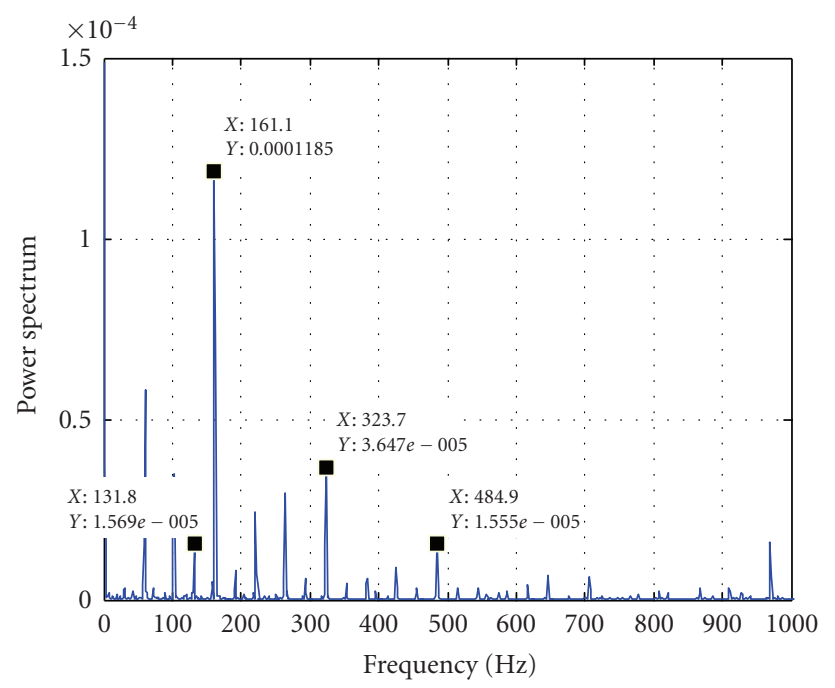

(b)

FIGURE 12: The vibration signal (a) and the corresponding TWPS (b) for rolling bearing with inner-race fault (CWRU data).

\section{APPENDIX}

\section{FAULT RELATED BEARING CHARACTERISTIC FREQUENCIES (BCF)}

Each bearing element has its own characteristic frequency of defect. Those frequencies can be calculated from the kinematics relation, that is, the geometry of the bearing and its rotating speed. For a bearing with a stationary outer race, the above defect characteristic frequencies can be obtained [14] as follows.

(i) Characteristic frequency of the outer race

$$
f_{o}(\mathrm{in} . \mathrm{Hz})=0.5 z f\left(1-\frac{d}{D} \cos \alpha\right)
$$

(ii) Characteristic frequency of the inner race

$$
f_{i}(\text { in. Hz })=0.5 z f\left(1+\frac{d}{D} \cos \alpha\right)
$$

(iii) Characteristic frequency of the rollers

$$
f_{r}(\text { in. Hz })=f \frac{D}{d}\left[1-\left(\frac{d}{D} \cos \alpha\right)^{2}\right]
$$

(iv) Characteristic frequency of the cage

$$
f_{C}=\frac{f}{2}\left[1-\frac{d}{D} \cos (\alpha)\right]
$$

where $z$ is the number of rollers, $d$ is the diameter of the rollers, $D$ is the pitch diameter, $\alpha$ is the contact angle, and $f$ is the rotating speed of shaft.

\section{REFERENCES}

[1] Z. Kiral and H. Karagülle, "Simulation and analysis of vibration signals generated by rolling element bearing with defects," Tribology International, vol. 36, no. 9, pp. 667-678, 2003.

[2] N. Tandon and A. Choudhury, "An analytical model for the prediction of the vibration response of rolling element bearings due to a localized defect," Journal of Sound and Vibration, vol. 205, no. 3, pp. 275-292, 1997.

[3] J. Antoni and R. B. Randall, "Differential diagnosis of gear and bearing faults," ASME Journal of Vibration and Acoustics, vol. 124, no. 2, pp. 165-171, 2002.

[4] P. D. McFadden and J. D. Smith, "Model for the vibration produced by a single point defect in a rolling element bearing," Journal of Sound and Vibration, vol. 96, no. 1, pp. 69-82, 1984.

[5] I. Antoniadis and G. Glossiotis, "Cyclostationary analysis of rolling-element bearing vibration signals," Journal of Sound and Vibration, vol. 248, no. 5, pp. 829-845, 2001.

[6] L. Li and L. Qu, "Cyclic statistics in rolling bearing diagnosis," Journal of Sound and Vibration, vol. 267, no. 2, pp. 253-265, 2003.

[7] R. B. Randall, J. Antoni, and S. Chobsaard, "The relationship between spectral correlation and envelope analysis in the diagnostics of bearing faults and other cyclostationary machine signals," Mechanical Systems and Signal Processing, vol. 15, no. 5, pp. 945-962, 2001.

[8] P. D. McFadden and J. D. Smith, "Vibration monitoring of rolling element bearings by the high-frequency resonance technique-a review," Tribology International, vol. 17, no. 1, pp. 3-10, 1984.

[9] R. B. Randall, J. Antoni, and S. Chobsaard, "A comparison of cyclostationary and envelope analysis in the diagnosis 
of rolling element bearing," in Proceedings of IEEE International Conference on Acoustics, Speech, and Signal Processing (ICASSP '00), vol. 6, pp. 3882-3885, Istanbul, Turkey, June 2000.

[10] D. Ho and R. B. Randall, "Optimization of bearing diagnostic techniques using simulated and actual bearing fault signals," Mechanical Systems and Signal Processing, vol. 14, no. 5, pp. 763-788, 2000.

[11] H. Qiu, J. Lee, J. Lin, and G. Yu, "Wavelet filter-based weak signature detection method and its application on rolling element bearing prognostics," Journal of Sound and Vibration, vol. 289, no. 4-5, pp. 1066-1090, 2006.

[12] D. F. Shi, W. J. Wang, and L. S. Qu, "Defect detection for bearings using envelope spectra of wavelet transform," ASME Journal of Vibration and Acoustics, vol. 126, no. 4, pp. 567-573, 2004.

[13] C. J. Li and J. Ma, "Wavelet decomposition of vibrations for detection of bearing-localized defects," NDT \& E International, vol. 30, no. 3, pp. 143-149, 1997.

[14] R. Rubini and U. Meneghetti, "Application of the envelope and wavelet transform analyses for the diagnosis of incipient faults in ball bearings," Mechanical Systems and Signal Processing, vol. 15, no. 2, pp. 287-302, 2001.

[15] C. Junsheng, Y. Dejie, and Y. Yu, "Time-energy density analysis based on wavelet transform," NDT \& E International, vol. 38, no. 7, pp. 569-572, 2005.

[16] W.-X. Yang and X.-M. Ren, "Detecting impulses in mechanical signals by wavelets," EURASIP Journal on Applied Signal Processing, vol. 2004, no. 8, pp. 1156-1162, 2004.

[17] J. Vass and C. Cristalli, "Optimization of Morlet wavelet for mechanical fault diagnosis," in Proceedings of the 12th International Congress on Sound and Vibration (ICSV '05), vol. 1, Lisbon, Portugal, July 2005.

[18] J. Lin and L. Qu, "Feature extraction based on Morlet wavelet and its application for mechanical fault diagnosis," Journal of Sound and Vibration, vol. 234, no. 1, pp. 135-148, 2000.

[19] H. Qiu, J. Lee, J. Lin, and G. Yu, "Robust performance degradation assessment methods for enhanced rolling element bearing prognostics," Advanced Engineering Informatics, vol. 17, no. 3-4, pp. 127-140, 2003.

[20] N. G. Nikolaou and I. A. Antoniadis, "Demodulation of vibration signals generated by defects in rolling element bearings using complex shifted Morlet wavelets," Mechanical Systems and Signal Processing, vol. 16, no. 4, pp. 677-694, 2002.

[21] C. Junsheng, Y. Dejie, and Y. Yu, "Application of an impulse response wavelet to fault diagnosis of rolling bearings," Mechanical Systems and Signal Processing, vol. 21, no. 2, pp. 920-929, 2007.

[22] W. J. Wang, "Wavelets for detecting mechanical faults with high sensitivity," Mechanical Systems and Signal Processing, vol. 15, no. 4, pp. 685-696, 2001.

[23] J. Lin and M. J. Zuo, "Gearbox fault diagnosis using adaptive wavelet filter," Mechanical Systems and Signal Processing, vol. 17, no. 6, pp. 1259-1269, 2003.

[24] L. C. Freudinger, R. Lind, and M. J. Brenner, "Correlation filtering of modal dynamics using the Laplace wavelet," in Proceedings of the 16th International Modal Analysis Conference (IMAC '98), vol. 2, pp. 868-877, Santa Barbara, Calif, USA, February 1998.

[25] Z. Yanyang, C. Xuefeng, H. Zhengjia, and C. Peng, "Vibration based modal parameters identification and wear fault diagno- sis using Laplace wavelet," Key Engineering Materials, vol. 293294, pp. 183-190, 2005.

[26] CWRU, Bearing Data Center, seeded fault test data. http:// www.eecs.case.edu/.

Khalid F. Al-Raheem received his B.S. (1987), and M.S. (1990) degree in production and metallurgical engineering from University of Technology, Iraq. He is currently a Lecturer at Mechanical and Industrial Engineering Department, Caledonian College of Engineering (CCE), Oman. Prior to joining CCE he was a Lecturer at Mechanical Engineering Department, UOT, Iraq (1991-2001). His research and teaching interests are in machinery condition monitoring and control system engineering. He is currently Ph.D. research student at Glasgow Caledonian University.

Asok Roy is Lecturer at the Glasgow Caledonian University. He holds an honors degree in mechanical engineering, M.S. degree in IT and completed his Ph.D. in Computer Vision Systems from Glasgow Caledonian University. He has years of industrial experience in process industry and his current research interests are in mechanical condition monitoring, computer vision systems, and $\mathrm{AI}$ applications.

K. P. Ramachandran has the B.E., M.Tech, and Ph.D. degrees. He is currently working as an Associate Dean (Academic), Caledonian College of Engineering, Muscat, Sultanate of Oman. He has been working more than 23 years in engineering institutions and as a consultant to many industries. He joined Caledonian College of Engineering (a university college) in 1997 where he has had variety of roles. He has obtained pro-

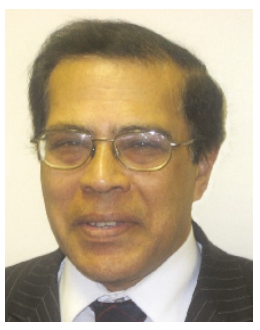
fessional qualification in mechanical engineering and specialized in the area of maintenance engineering and management. He has research interest in the vibration instrumentation and measurement, analysis and control; condition monitoring of rotating machines. He has many publications in his credit and has been conferred Sir C. V. Raman award for the best technical paper published in the Journal of Vibration and Acoustics (1997). He is a Member of ASME, Life Member in the Indian Society of Technical Education, Member of Institution of Plant Engineers India.

D. K. Harrison received the B.S. degree with honours, M.S., Ph.D., CEng FIEE, FIMechE, FIES, CITP, and MBCS degrees. He is currently the Acting Dean of the School of Engineering, Science and Design within Glasgow Caledonian University. He has spent most of his working career in the manufacturing industry. A graduate of UMIST, he has also worked within the Department of Mechanical Engineering at UMIST, where

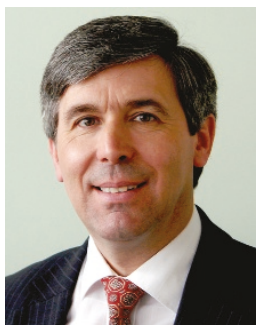
he was a Consultant to many blue chip manufacturing companies. He joined Glasgow Caledonian University in 1994 where he has had a variety of roles. He is currently involved with a number of research projects, principally with industrial organisations, all of 
which have the common theme of design and manufacturing optimization. This activity has led to him having successfully supervised 23 Ph.D. students through to graduation. He is the joint author of the widely used textbook "Systems for Planning and Control in Manufacturing." He has also edited several other books and conference proceedings and has published his work widely.

Steven Grainger is a Lecturer in Signal Processing at Glasgow Caledonian University. He holds undergraduate degrees in electronic engineering and computing and received his Ph.D. degree from Glasgow Caledonian on the application of DSP for the optimization of motor drives. His teaching and research interests lie in the areas of DSP, motor drives, condition monitoring

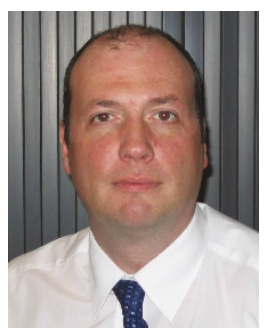
and digital watermarking and he has been a Visiting Lecturer at Wismar University, Germany; Tomsk Polytechnic University, Siberia, and the University of Adelaide, Australia. 